\title{
1987 Highlights
}

\author{
Kathleen C. Taylor \\ MRS President
}

This issue of the MRS BULLETIN is the last issue to be published in 1987 and as such marks the end of my year as MRS President. Throughout 1987 the Materials Research Society continued its trend of astonishing growth. We can put the label "largest ever" on almost every activity the Society sponsored this year. I owe tremendous thanks to many persons through whose efforts this growth was accomplished. To name them all would number in the hundreds. A special thanks go out to our committee chairs (Dave Campbell, Clif Draper, Carol Jantzen, Elton Kaufmann, Julia Phillips, Gordon Pike, Rod Quinn, Mike Quick, Jim Roberto, Al Romig, and Gary Tibbetts), our 1987 meeting chairs (Russ Chianelli, Graham Hubler, and Greg Olson who ran the Spring MRS Meeting and Murray Gibson, Tom Picraux, and Barry Scheetz who ran the Fall MRS Meeting), and the many symposium chairs.

MRS membership reached 5,952 in 1987. The MRS BULLETIN under the leadership of editor Elton Kaufmann expanded to 8 issues. A full-time technical editor will join the MRS BULLETIN staff in 1988. Walter Brown assumed the duties of Editor in Chief of Journal of Materials Research at the first of the year. JMR experienced an ever increasing copy flow and expanded its circulation during 1987. The topical coverage in JMR has grown, but we have more work to do to reach the wide topical distribution characteristic of our meetings. In 1987 MRS published 27 books, including 25 meeting proceedings. The MRS Headquarters staff has grown overall from 10 to 15 persons during 1987 in order to handle the growth of the Society, mostly in its publications.

The size of MRS meetings grew by $19 \%$ based on the number of papers presented, and poster sessions have achieved a growing popularity. We demonstrated tremen-

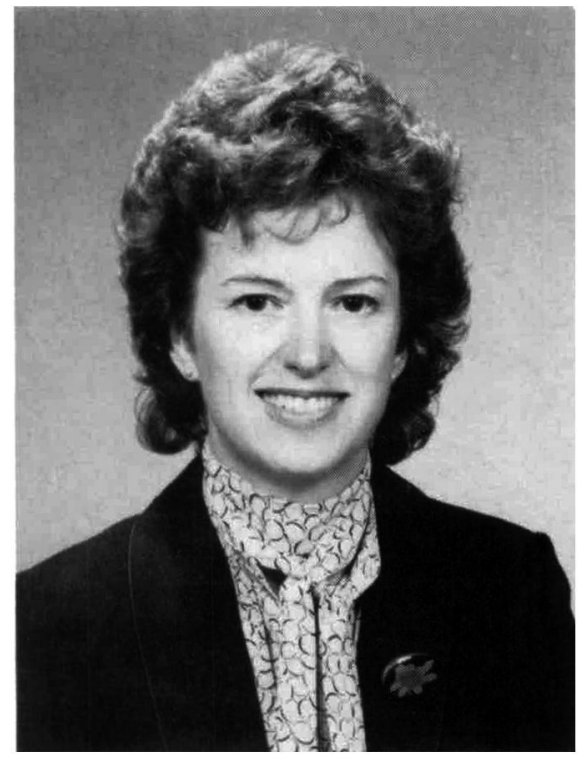

dous flexibility in accommodating two large symposia on high temperature superconductors at the Spring and Fall MRS Meetings. The symposium held at the

\section{MRS membership reached 5,952 in 1987.}

Spring Meeting was added after the initial program announcement. A video tape of this symposium was offered for sale after the meeting. The Fall Meeting symposium on high temperature superconductors offered a late abstract submission date and a late program announcement.
The opportunity for meeting attendees to meet with equipment manufacturers at our meetings was expanded. At the MRS Spring Meeting in Anaheim an MRS Equipment Show was held for the first time at an MRS Spring Meeting. An extension was added to our Equipment Show at the Fall MRS Meeting after the 120 booths originally available sold out several months before the meeting.

The MRS Short Course program at MRS meetings expanded from 39 courses offered in 1986 to 50 courses offered in 1987. Several courses were offered apart from the MRS meeting as part of the OnSite Short Course Program.

During 1987 an organizational meeting of the International Materials Research Committee took place at the E-MRS meeting followed by a second meeting at the 1987 Fall MRS Meeting. This group promises to assist in the coordination of activities among groups worldwide that sponsor multidisciplinary technical meetings on materials research.

New MRS Student Chapters were formed in 1987 at Alfred University, the University of Florida, the University of Minnesota, and the University of Michigan. There are now 14 MRS Student Chapters and 7 local Sections.

During 1987 I had the privilege to work with an especially talented, innovative, and very hard working group of persons on the MRS Executive CommitteeGordon Pike, John Baglin, Bob Chang, Julia Phillips, and Sue Kelso-- all of whom deserve recognition for their contributions to the management of the Society in 1987. We can look forward to another year of growth for MRS in 1988, given the work already in progress by our outstanding volunteers and our diligent staff at MRS Headquarters.

\section{"The Race for the Superconductor"}

\author{
Tuesday, March 29, 1988, 8:00 p.m. \\ PBS Television
}

Featuring the developments in high temperature superconductivity during the past year and the role of the Materials Research Society in these events. 


\section{When Your Research Is So Important, Why Compromise On Sample Preparation?}

South Bay Technology has been providing the materials research community with superior sample preparation equipment for over 22 years. By designing and manufacturing our own equipment, we have built a reputation for uncompromising quality, precision and service. By listening to your needs, we have been able to meet your

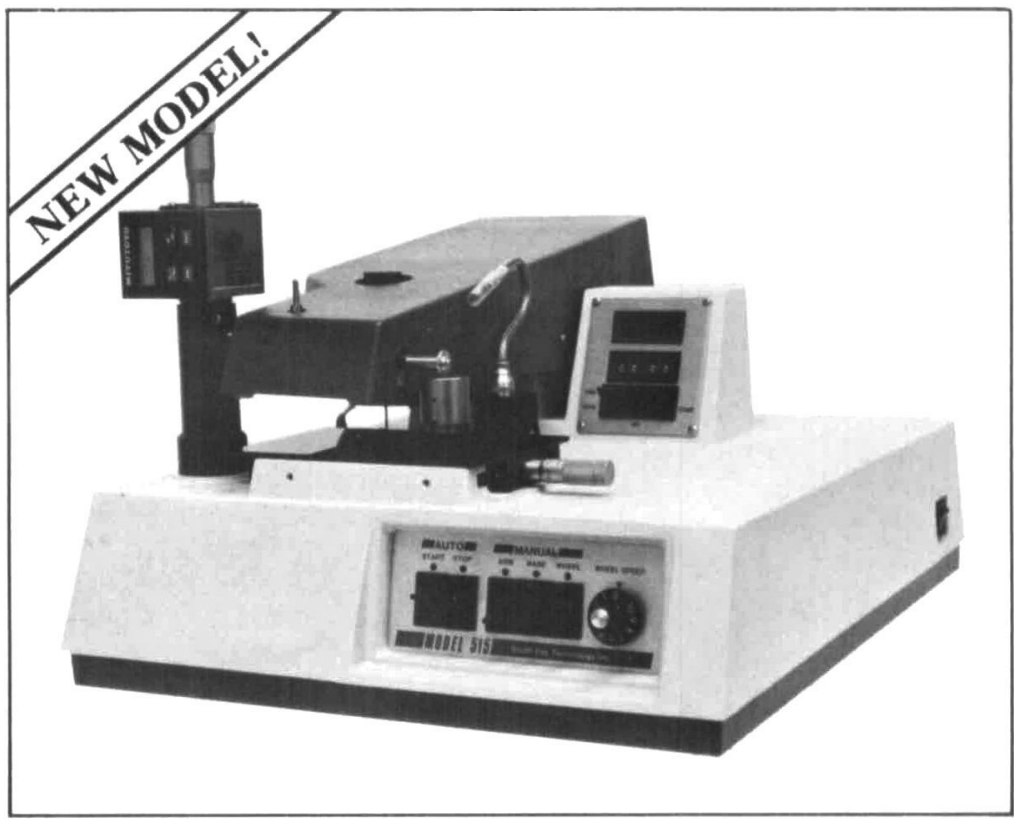

SBT MODEL 515 Precision Dimpling Instrument for TEM Specimen Preparation. requirements for design and performance-time and time again!

- Slicing Instruments

- Lapping \& Polishing Instruments

- Orientation Instruments
- TEM Sample Preparation Instruments

- Wafer Mounting Fixtures

- Sample Preparation Supplies

\section{WHY COMPROMISE?}

\section{SBT \\ SOUTH B BAY \\ TECHNOLOGY inc. \\ (818) $442-1839$

Australia/New Zealand Imbros Pty. Ltd.

9 Warwick Street

G.P.O. Box 917

Hobart, Tasmania 7001

Phone: 34 9899/Telex: 58092

Fax: 344532

\section{France}

Cryophysics, SA

9, Rue Dallery

Jouy-En-Josas, F-78350, France

Phone: 39-56-00-66/Telex: 696096
Austria/West Germany

Cryophysics GmbH

Landwehrstrasse 48

Darmstadt D-6100, West Germany

Phone: (06151) 86281/Telex: 419594

Fax: (6151) 84481

\section{Japan}

Meiwa Shoji Co., Ltd.

Tenshin Building

12-14, Kyomachibori 1-Chome

Nishi-Ku, Osaka 550 Japan

Phone: 06-448-3474/Telex: 64849

Fax: 816-447-0074
China

Global Technology

Xiyuan Hotel Room 919

Xijiao, Erligou

Beijing, China

Phone: 890721 Ext. 919

Telex: 22831

United Kingdom

Testbourne Ltd.

9 Sheppard Road

Basingstoke, Hampshire

RG21 3HT, England

Phone: (STD 0256) 467055

Telex: 858029 